\title{
Chasing Rabbits:
}

\section{Understanding "Urbanized"}

Writer: Melissa Cloutier*

Grant MacEwan University, Canada

\begin{abstract}
Poetry can be a voice for concerns about conservation and urbanization's effects on habitat and animals, whether domestic or wild, as well as an inspiration for researching local urbanization. The concept of poetry as an expression of perspective and feeling about our ever-changing environment that is continuously losing its natural state is shared within this article.
\end{abstract}

\section{Urbanized}

Then:

Deteriorating house, one-

story? white chipped siding, farther

back on the lot; gusty, strawberry-scented

fields, hip-long sun-warmed grass; hundreds

of soft, white rabbits - a colony

adopting the land — started: one pair, grew

to hundreds of those gentle, white rabbits. 


\section{Now:}

Modern grey building, sun-warmed con-

crete? The harsh smell of asphalt,

paved parking lot, no fields, vehicles replace

rabbits, prickly manicured grass.

What of those white

rabbits?

\section{As I Remember It}

In high school, I had a close friend named Laura. She knew I was an animal lover. I would frequently drive around with her and her current boyfriend Scott, and one day she told me of an abandoned house by a Ford dealership between Edmonton and St. Albert that had been claimed by rabbits.

Laura and Scott showed me this place of rabbits. Scott parked on $156^{\text {th }}$ Street, beside the lot and across from the Ford dealership. After sitting in the vehicle for a little while, we spotted some white rabbits hiding in the tall grass around the old, abandoned one-level house. Laura's theory was that rabbits had inhabited the home and then they continued to multiply and grow when the owners had moved on from the property. My thoughts and observations of this recount are that the rabbits are one with nature, and nature had decided to take back its land.

Years later, when my mom and I were driving down St. Albert Trail into Edmonton, I was reminded of the lot with its rabbits and I noticed that the abandoned house had been torn down. The rabbits sprung back into my mind, along with the question: "what of those white rabbits?"

\section{The Question}

This question festered in my mind for quite some time, and the question sprouted more questions. Did anybody care what happened to the white rabbits? Why do we shove our wildlife further outside the city and replace habitat with similar, already existing business or with highways that create more traffic? The redevelopment of this 
lot reminded me of the Anthony Henday highway that was being built between St. Albert and Edmonton, and of how there used to be fields with horses and deer and coyotes and bird nests and homes for wildlife where now there is only stretches of concrete.

What of the animals that lose their home to our urbanization? And so the question- "what of those white rabbits?"- dwelled in me for so long that I felt the need to write about the situation to try to evoke my own questioning into others.

\section{The Method}

When something burdens me for so long, I often struggle with wrapping my mind around what exactly I want to say. In the case of "Urbanized," I wasn't sure what I wanted to say or why. I just knew I was bothered by the disappearance of the house and its residing rabbits, and I wanted to encapsulate my being bothered. When unsure of what or how to say something, I often move towards poetry because it allows me to express thoughts without restriction. I have previously described poetry as dancing: it is

something that is felt; it is expressing feelings and emotions. Dancing is a natural movement that occurs when music and body are one: with "Urbanized" my mind was one with my pen and the words released from me naturally.

The only thing planned for in "Urbanized" was the structure. I wanted to contrast the before and after, natural versus human-made, animal versus human. The best way for me to do this was to show what I was continuously visualizing, which, in sum, was the before and the after, the loss of nature.

When reading "Urbanized," it must be taken into account that there were no strawberry-scented fields; perhaps the house was not white and the new building is not grey. Perhaps the rabbits aren't wild but are indeed domesticated, and maybe there were some fields remaining on the lot after the house had been removed. These details and adjustments were added for poetic emphasis and visual contrast. The point is that this place was once home to rabbits and their home was taken away. Where have all the rabbits gone? Why are our desires for buildings, businesses and transport so often prioritized over habitat and wildlife? Is habitat and wildlife considered when an area is chosen for urbanization?

"Urbanized" is a qualitative poem that centralizes around comparing before and after. Hence, I was not focusing on fact when writing. I was focusing on what the property represents to me-a loss of nature.

ECJ Volume 2, No. 1, 2012 


\section{The Result}

My reason for writing "Urbanized" was to unburden my troubled mind and also to try to evoke the same feeling in other people. The goal of the poem is for readers to care about the rabbits, to wonder about their whereabouts, to feel the loss of land. Also, I aimed for the lot to be remembered as a home for rabbits during a less urbanized period of time. Most importantly, I hope that "Urbanized" will be an example of what happens on a daily basis because every day we are losing nature to urbanization.

\section{The History}

Discovering the rabbits' history was a journey. I felt overwhelmed when advised to learn the background of the property, and especially when and how the rabbits came to be a colony that recently diminished.

To begin, I tried to contact my old friend, Laura, without success. Then I attempted to research the property. I waited to find out what the new building was going to be (signs were soon posted identifying the Christ City project), and then I tried searching the site via the Province of Alberta Land Titles online to no avail. So I ventured to the property of the new building with the intention of speaking with some workers. All of these pursuits led me to a wall.

I had one other lead to follow. This lead was City Ford Sales, which is located across the street from Christ City. I hoped there would be someone who had worked there long enough to remember the previous property and the rabbits it fostered. After all, there had been hundreds of rabbits - someone must have noticed and remember them. So my friend and I went across the street to inquire about the property and the rabbits, and from there the journey proceeded.

Upon walking up to the building, a friendly salesperson approached my friend and I to ask if we were interested in trading my friend's Ford. We laughed and I explained that I was a student from Grant MacEwan University, and that I was researching the property across from the dealership and was hoping someone could answer a few questions for me. He seemed to perk up, telling us to follow him. We entered the building and soon spoke to a secretary who recalled an old farmhouse on the property before the Christ City Church project had begun about a year ago. She also knew of the rabbits, and the salesperson and secretary laughed over how the rabbits who came over to the dealership took over in their own way.

ECJ Volume 2, No. 1, 2012 
While speaking with the secretary, my friend noticed someone she knew in the dealership and began speaking with him. The salesperson mentioned that I might want to speak to this person as well because he had been around the company for a while. This person was Chris Goodwin, who is an auto detailer and whose father is manager at City Ford Sales. Once we began talking, he explained that the rabbits came from the former farmhouse across the street, and that they have a little house behind the building where people feed them. I was instantly intrigued by this, and asked to see the house.

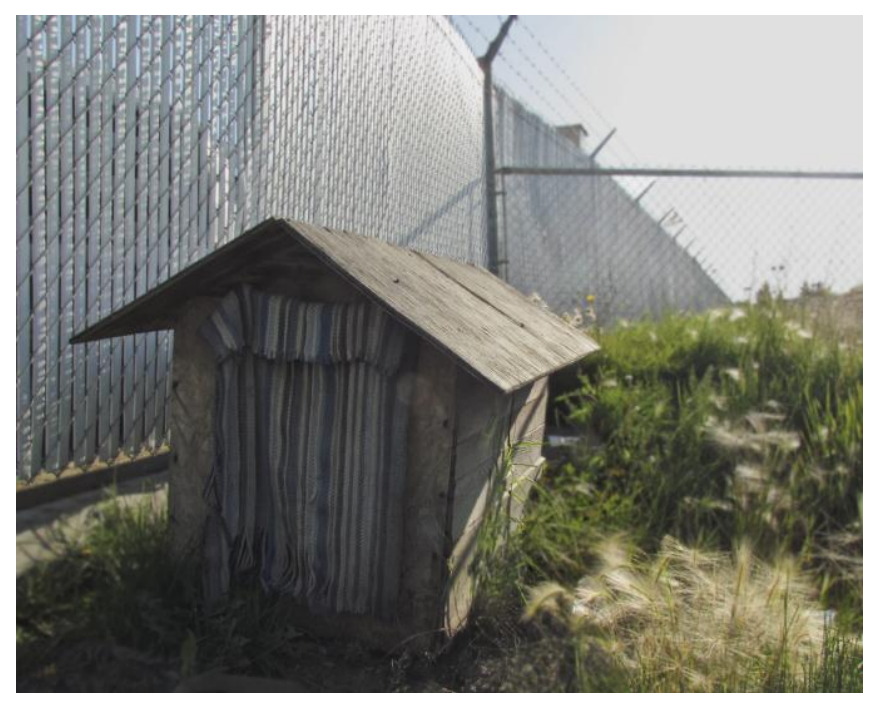

Chris eagerly agreed to show us the house, and on the way I learned that the rabbits had been around for approximately twenty years. We walked up to two water tanks set side-by-side. Chris explained that someone from Ron Hodgson (another dealership that is located beside City Ford Sales) had brought the tanks for the rabbits to make home in. While explaining that many people bring feed for the rabbits, a van pulled up. A couple stepped from the van, opened up the trunk and started bringing out trays of feed. Chris suggested I speak with them, as they were some of the people who fed the rabbits.

The woman, Marilyn Tkachuk, was warm and welcoming as we began chatting. She explained that her and her spouse drop off seven trays per day of vegetables, fruit, rabbit pellets and pita bread to name a few, which normally takes about 45 minutes. They have made this a daily routine for the past six years. She originally learned of the rabbits via watching TV, and Chris verified this by recalling that City Ford Sales used to advertise the rabbits. When Marilyn first learned of the rabbits she visited the location to see them, and from there her and her husband began buying food to bring for the rabbits until the couple eventually found a supplier to provide leftover food. She also explained that the rabbits are territorial and have their own groups. These groups use specific 
feeding trays so the rabbits aren't necessarily a colony but rather a community of individual family units.
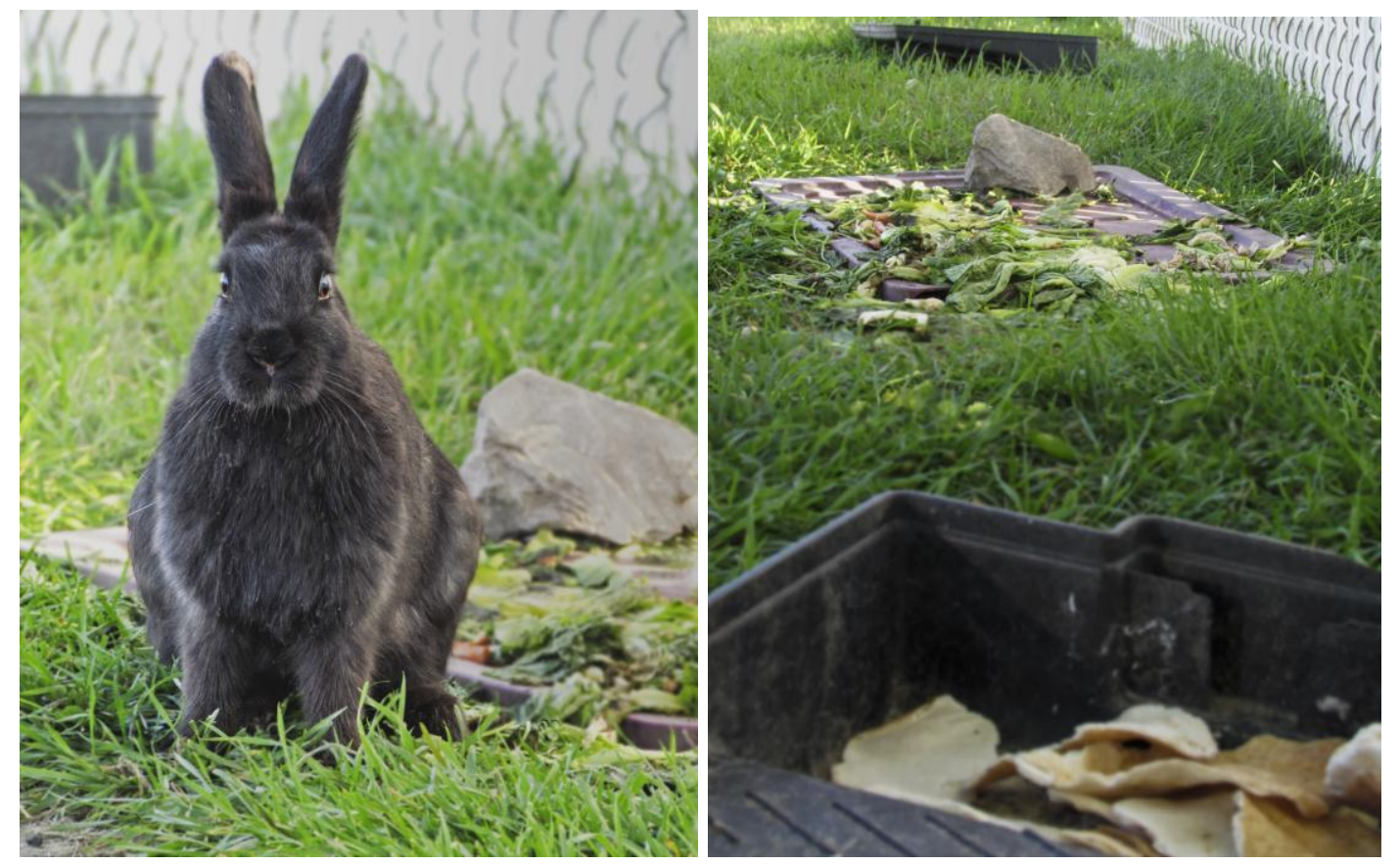

During our conversation, I also learned that most of the rabbits were not wild white rabbits or hares like I recalled. Instead, the majority of them were domesticated loppedeared black, brown, grey and white rabbits. I learned that even though the rabbits often cross $156^{\text {th }}$ street (a very busy roadway), they are rarely hit. She mentioned that people had dropped the pets off there over the years and that there had been hundreds, but that number had reduced in the past year (predators are suspected to be the cause). She explained that this seemed like it might be a natural population cycle though as the rabbits had been reduced to approximately five in one year, yet their numbers increased again after their breeding period.

Around this point, I inquired again about how the rabbits had originated. Apparently the owner of the former farmhouse had also owned rabbits and let them roam freely. Their numbers multiplied over time, and when the owner left the house, he left the rabbits with it. They continued to multiply and and eventually took over the abandoned property.

I asked Chris about the boundaries of the property and when it was sold, finding that the province had actually bought the property with Christ City Church only owning a small portion of the land in that area. Anthony Henday highway would consume the rest 
of the area. He also mentioned that the province offered, multiple times, to purchase the property from the landowners, and specifically the farmhouse owner, before the offer was accepted. Originally, the owners did not want to sell but they eventually gave in to what seemed to be either persistence or "the right price" or both. Apparently, the province moved a house for the owner who used to live beside the former farmhouse when they finally accepted the province's offer.

And so, at the end of my journey through the history of the property I learned that the rabbits are still around. People feed them. People do care about them. Though there is still the impending Anthony Henday highway, and, in my opinion, its development is a threat to these rabbits and the other wildlife that live on the land that is being urbanized.

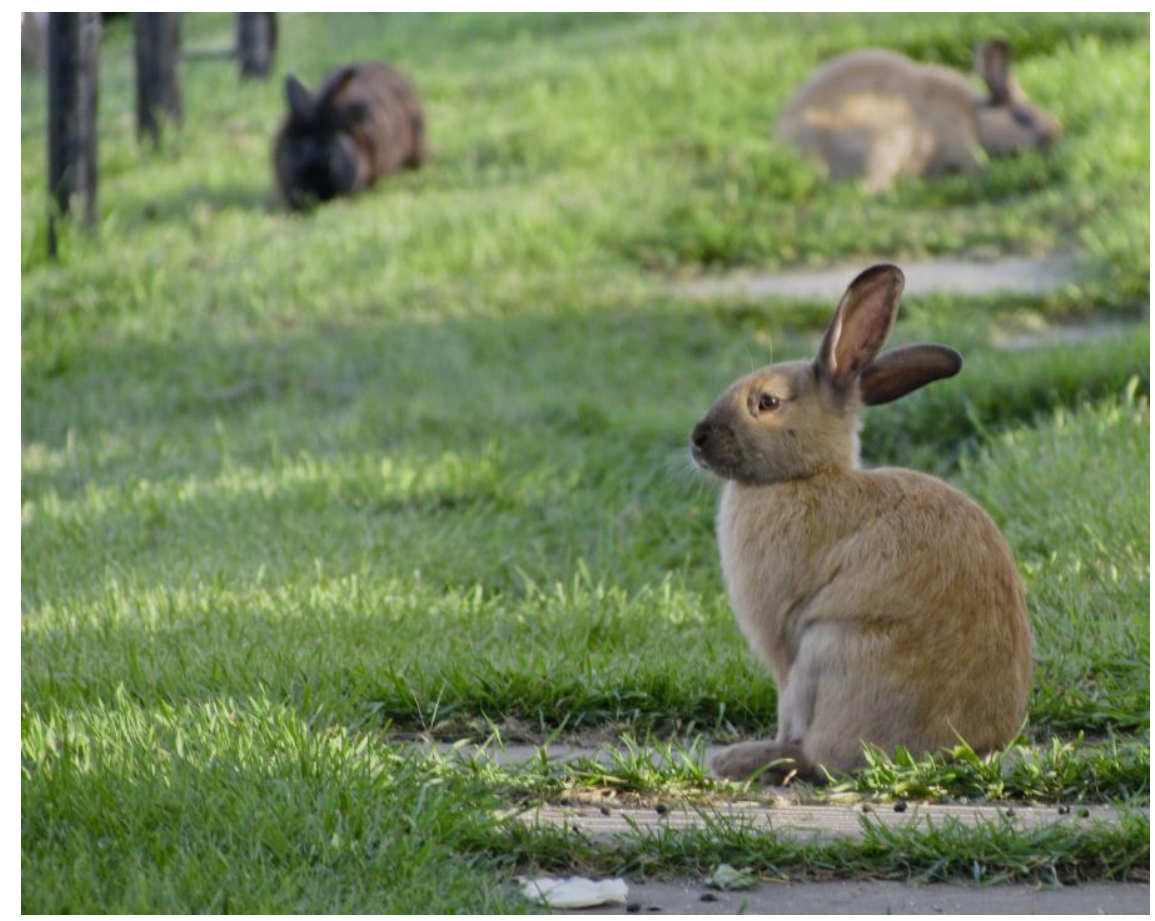

\section{Conclusion}

Though I found some discrepancies between how I remembered the rabbits and their home versus the history that I learned, I still feel my poem is relevant. Even if the rabbits are domesticated, they are still animals, and there are other animals in the area that are also losing their home and habitat to the construction of the Anthony Henday highway. The construction of this highway and the Christ City church represent urbanization. The animals living in this area lose a large portion of their habitat because 
of the construction of this highway, and the scope of fields and natural area continues reducing, narrowing and closing-in as urbanization continues.

Merriam Webster's definition of urbanize is "to impart an urban way of life to <urbanize migrants from rural areas>." One consideration I have is that the habitat of wildlife and animals is not necessarily being lost but rather the nature of their home changes, and therefore adaption and a new form of survival is forced upon the animals living within an area when urbanization occurs. The influence on lifestyle of such wildlife because of urbanization needs to be considered.

Continued urbanization requires more people like Marilyn and Chris who remember, care and think about these animals. "Urbanized" is meant to evoke such imagining, reminiscing, and caring in its readers. Most importantly it is meant to evoke considerations of our land and how we affect it when we use and alter it. In the words of Steve Irwin, "I believe our biggest issue is the same biggest issue that the whole world is facing, and that's habitat destruction," (as cited in saichp1, 2007). Furthermore, I believe poetry can be a tool for expressing the need for conservation and how urbanization jeopardizes conservation and the well-being of animals when prioritized.

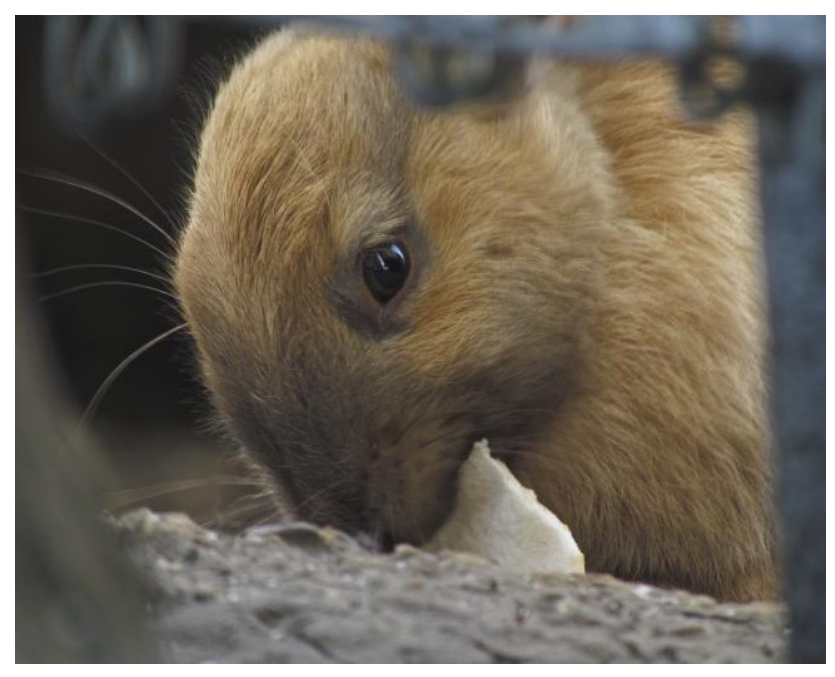

*Writer and Photographer: Melissa Cloutier is a fourth year student in the Bachelor of Applied Communications in Professional Writing program. She has a passion for writing, photography, and the environment. 


\section{References}

Goodwin, C. (Spring, 2011). Interview.

saichp1. (November 13, 2007). In env-go. Other Info hdsp1. Retrieved from http:/ / envngo.wikispaces.com/page/code/Other+Info+hdsp1.

Tkachuk, M. (Spring, 2011). Interview.

Urbanize. (2011). In Merriam-Webster's online dictionary. Retrieved from

http:/ /www.merriamwebster.com/dictionary/urbanized? show =0\&t=1304715488. 